\title{
Systemic thromboembolism including multiple cerebral infarctions with middle cerebral artery occlusion caused by the progression of adenomyosis with benign gynecological tumor: a case report
}

Ryo Aiura ${ }^{1 *}$, Sadayoshi Nakayama ${ }^{2}$, Hroo Yamaga ${ }^{3}$, Yu Kato $^{3}$ and Hirotake Fujishima ${ }^{3}$

\begin{abstract}
Background: Adenomyosis, a benign gynecological disease, causes cerebral infarction. Similar to Trousseau's syndrome, it elevates cancer antigen 125 (CA125) and D-dimer levels; causes hypercoagulability; and results in cerebral infarction. However, no case of adenomyosis causing major cerebral artery occlusion and requiring endovascular thrombectomy has yet been reported. We report on a woman with middle cerebral artery occlusion caused by adenomyosis progression with a benign gynecological tumor and recurrent cerebral infarction. She was successfully treated by endovascular thrombectomy and hysterectomy.

Case presentation: A 48-year-old woman with heavy uterine bleeding was transported by ambulance to our hospital. Upon arrival, she presented with impaired consciousness. Laboratory test results revealed decreased hemoglobin $(8.2 \mathrm{~g} / \mathrm{dL})$ and elevated D-dimer $(79.3 \mu \mathrm{g} / \mathrm{mL})$ levels. Radiological imaging revealed adenomyosis, a left ovarian tumor, multiple uterine myomas, and old and new bilateral renal infarctions. She experienced repeated episodes of excessive menstruation caused by adenomyosis and was scheduled for hysterectomy in 2 months at another hospital. After hospital admission, uterine bleeding stopped. However, 5 days after initial bleeding, she had another episode of heavy uterine bleeding and developed left hemiparesis and dysarthria 20 min later. Brain magnetic resonance imaging revealed bilateral multiple cerebral infarctions indicating right middle cerebral artery occlusion. Thus, endovascular thrombectomy was performed, and anticoagulant therapy was administered. Laboratory test results after thrombectomy revealed elevated CA125 (3536 U/mL) and CA19-9 (892 U/mL) levels. She was at a risk of recurrent heavy uterine bleeding leading to repeated cerebral infarction because of anticoagulant treatment. Therefore, we performed hysterectomy and ovariectomy 11 days after initial bleeding. Histopathological assessment revealed no malignancy. Although she developed asymptomatic pulmonary thromboembolism 14 days after initial bleeding, D-dimer and tumor marker levels returned to normal soon after gynecological surgery. At 15 months post-surgery, she had not experienced further ischemic events.

(Continued on next page)
\end{abstract}

\footnotetext{
*Correspondence: imaiuuu795@gmail.com

'Department of Neurosurgery, AOI Universal Hospital, 2-9-1, Tamachi,

Kawasaki Ward, 210-0822 Kawasaki City, Kanagawa, Japan

Full list of author information is available at the end of the article
}

(c) The Author(s). 2021 Open Access This article is licensed under a Creative Commons Attribution 4.0 International License, which permits use, sharing, adaptation, distribution and reproduction in any medium or format, as long as you give appropriate credit to the original author(s) and the source, provide a link to the Creative Commons licence, and indicate if changes were made. The images or other third party material in this article are included in the article's Creative Commons licence, unless indicated otherwise in a credit line to the material. If material is not included in the article's Creative Commons licence and your intended use is not permitted by statutory regulation or exceeds the permitted use, you will need to obtain permission directly from the copyright holder. To view a copy of this licence, visit http://creativecommons.org/licenses/by/4.0/ The Creative Commons Public Domain Dedication waiver (http://creativecommons.org/publicdomain/zero/1.0/) applies to the data made available in this article, unless otherwise stated in a credit line to the data. 
(Continued from previous page)

Conclusions: Adenomyosis with benign gynecological tumors may be associated with elevated D-dimer and tumor marker levels; excessive menstruation; and anemia. It may cause systemic thromboembolism, including cerebral infarction. To our knowledge, no other study has reported that adenomyosis causes major cerebral artery occlusion requiring endovascular thrombectomy. Hysterectomy may be an effective radical treatment of this condition.

Keywords: Adenomyosis, Benign gynecological tumor, Hypercoagulability, Systemic thromboembolism, Multiple cerebral infarction, Middle cerebral artery occlusion, Endovascular thrombectomy, Hysterectomy

\section{Background}

Adenomyosis is not a life-threatening gynecological disease. However, it causes excessive menstruation, dysmenorrhea, and menstrual pain. Adenomyosis has also been reported to elevate cancer antigen 125 (CA125) and D-dimer levels, cause hypercoagulability, and result in development of cerebral infarction (CI), similar to Trousseau's syndrome that is caused by malignant tumor [1-8]. In previously reported cases, most CIs were caused by peripheral vessel occlusion or stenosis of a major cerebral artery. To the best of our knowledge, no other study has reported that adenomyosis causes major cerebral artery occlusion requiring endovascular thrombectomy. Herein, we present our experience with systemic thromboembolism, including multiple CIs with middle cerebral artery occlusion. It resulted from progression of adenomyosis accompanied by multiple uterine myomas and ovarian endometriosis. Recurrent CI was successfully prevented by endovascular thrombectomy and hysterectomy.

\section{Case presentation}

A 48-year-old woman was transported by ambulance to our hospital for heavy uterine bleeding and impaired level of consciousness. She had no underlying conditions except for adenomyosis, for which she was scheduled to undergo hysterectomy in 2 months at another hospital due to recurrent excessive menstruation. Upon arrival, her Glasgow Coma Scale was E4V4M6, and she was pale. She had a fever of $39.1{ }^{\circ} \mathrm{C}$. Laboratory test results revealed a decreased hemoglobin concentration $(\mathrm{Hb})(8.2 \mathrm{~g} / \mathrm{dL}$; normal 10.8-14.9 g/dL) and elevated D-dimer levels $(79.3 \mu \mathrm{g} /$ $\mathrm{mL}$; normal $<1.0 \mu \mathrm{g} / \mathrm{mL})$, white blood cell count (WBC) $(18,060 / \mu \mathrm{l}$; normal $3300-8600 / \mu \mathrm{l})$, and Creactive protein level (CRP) $(20.1 \mathrm{mg} / \mathrm{dL}$; normal < $0.3 \mathrm{mg} / \mathrm{dL})$. Contrast-enhanced computed tomography (CT) and magnetic resonance imaging (MRI) of the pelvic area revealed adenomyosis; left ovarian tumor; multiple uterine myomas; and both old and new bilateral renal infarctions (Fig. 1a-d). She was admitted to the gynecology department and administered an antibiotic agent (200 mg/day cefmetazole sodium) for 5 days. She denied a history of hypertension, hyperlipidemia, or diabetes based on her annual medical checkups as well as a family history of cerebrovascular disease. One day after admission, uterine bleeding stopped, and her consciousness improved. However, her $\mathrm{Hb}$ levels furtherly decreased to $6.9 \mathrm{~g} / \mathrm{dL}$. Therefore, 4 units of red blood cell concentrates were transfused.

However, 5 days after the initial bleeding, she had another episode of heavy uterine bleeding, and 20 min later, she became unconscious with left hemiparesis and dysarthria. Her National Institutes of Health Stroke Scale (NIHSS) score was 13. Brain MRI revealed bilateral multiple CIs indicating right middle cerebral artery occlusion. In addition, her diffusionweighted image Alberta Stroke Programme Early CT Score was 6. Endovascular thrombectomy was subsequently performed, and her Thrombolysis in Cerebral Infarction grade was 3 (Fig. 2a-f). After endovascular therapy, her NIHSS score improved to 2. Heparin was administered as anticoagulant therapy to prevent CI. Transesophageal echocardiography did not reveal any evidence of patent foramen ovale or valvular vegetation. Moreover, a 24-h Holter electrocardiogram did not show atrial fibrillation or any other arrhythmia. Due to her underlying gynecological tumor, additional laboratory testing for tumor markers were performed the day after thrombectomy. These results revealed elevated CA125 (3536 U/mL; normal $<35.0 \mathrm{U} / \mathrm{mL})$ and CA19-9 (892 U/mL; normal $<37.0 \mathrm{U} / \mathrm{mL})$ levels. Levels of protein $S$, protein $C$, lupus anticoagulant, Factor $\mathrm{V}$ coagulation activity, anticardiolipin antibody, anti-cardiolipin-beta-2-glycoprotein complex antibody, and carcinoembryonic antigen were within normal range.

We were concerned that using heparin might cause heavy uterine bleeding and that could have led to repeated CI. Since she was scheduled for a hysterectomy in 2 months at another hospital, with her consent, 

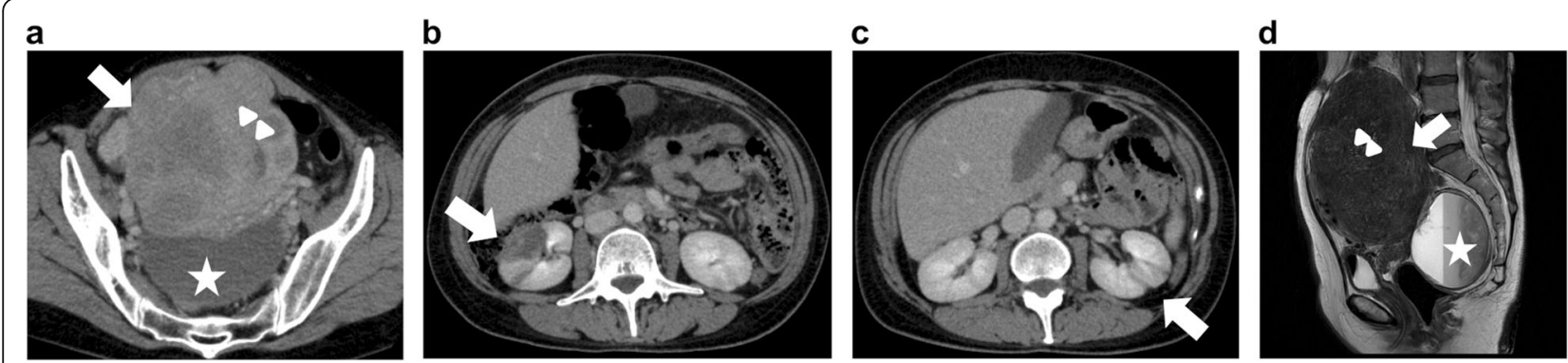

Fig. 1 Pelvic imaging on the day of initial bleedinga, d Pelvic contrast-enhanced computed tomography (CT) and magnetic resonance images show adenomyosis (arrowheads), multiple uterine myomas (arrows), and a left ovarian tumor (stars). b-c Pelvic contrast-enhanced CT shows old and new bilateral renal infarctions (arrows)
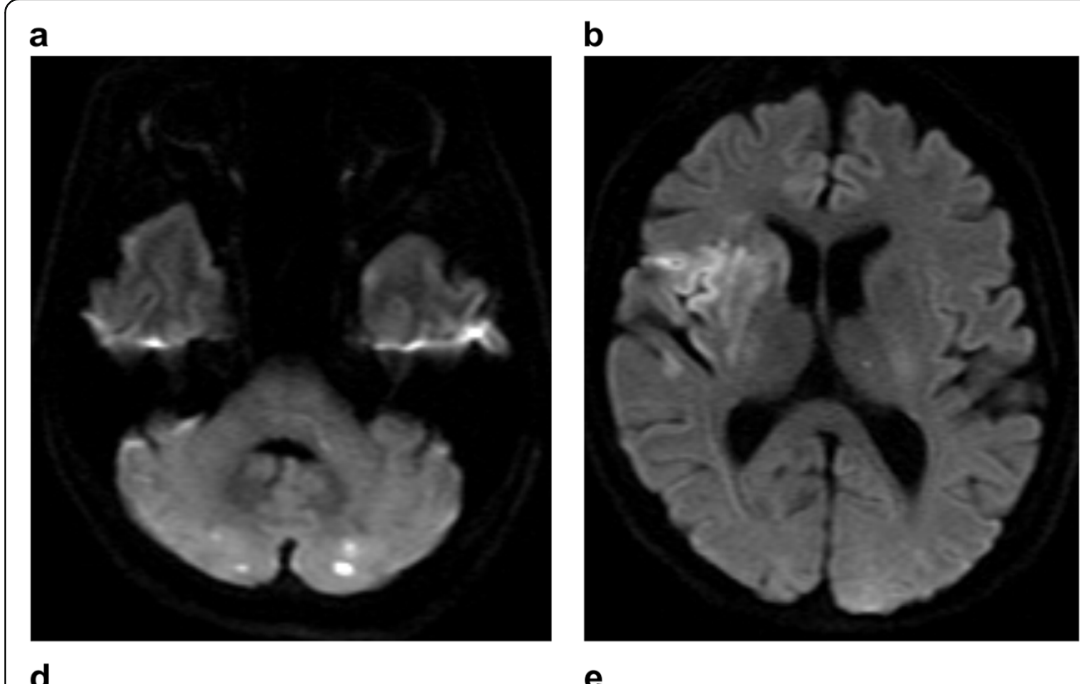

\section{C}

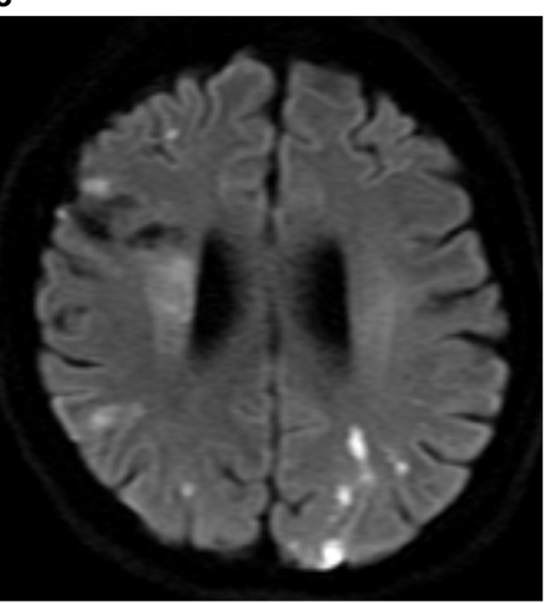

e

$\mathbf{f}$
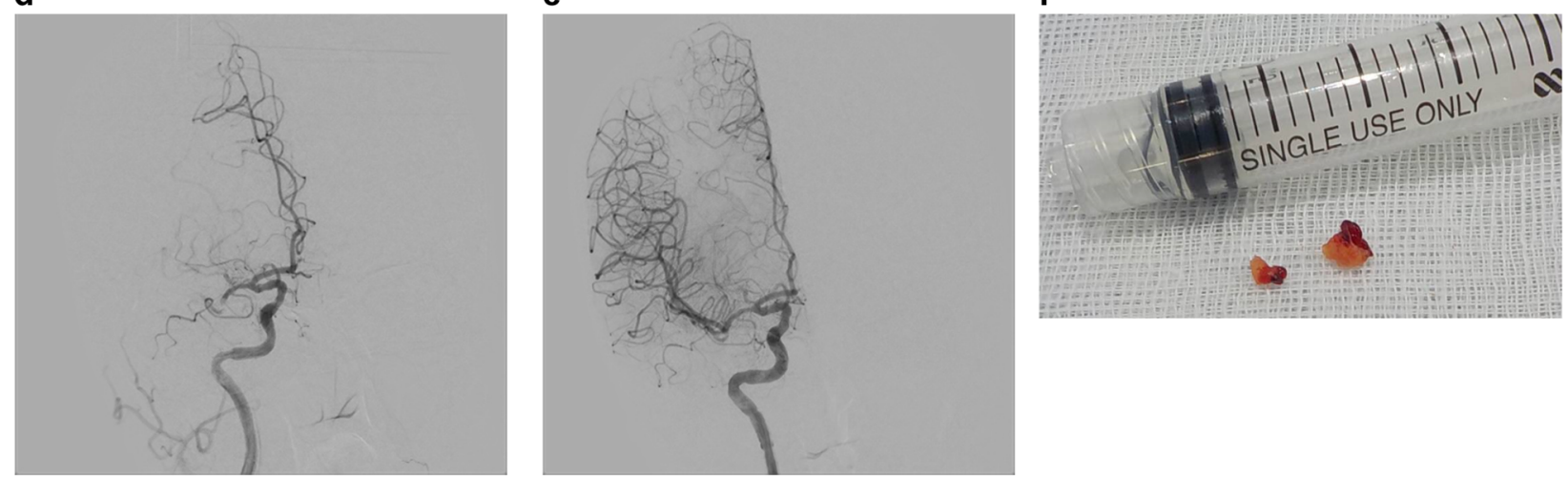

Fig. 2 Brain imaging and thrombus collected on the day of the development of cerebral infarctionsa-c Brain magnetic resonance imaging shows bilateral multiple cerebral infarctions indicating right middle cerebral artery occlusion. d, e Right internal carotid artery angiography shows right cerebral artery occlusion, and thus, we performed endovascular thrombectomy. $\mathbf{f}$ The collected thrombus 


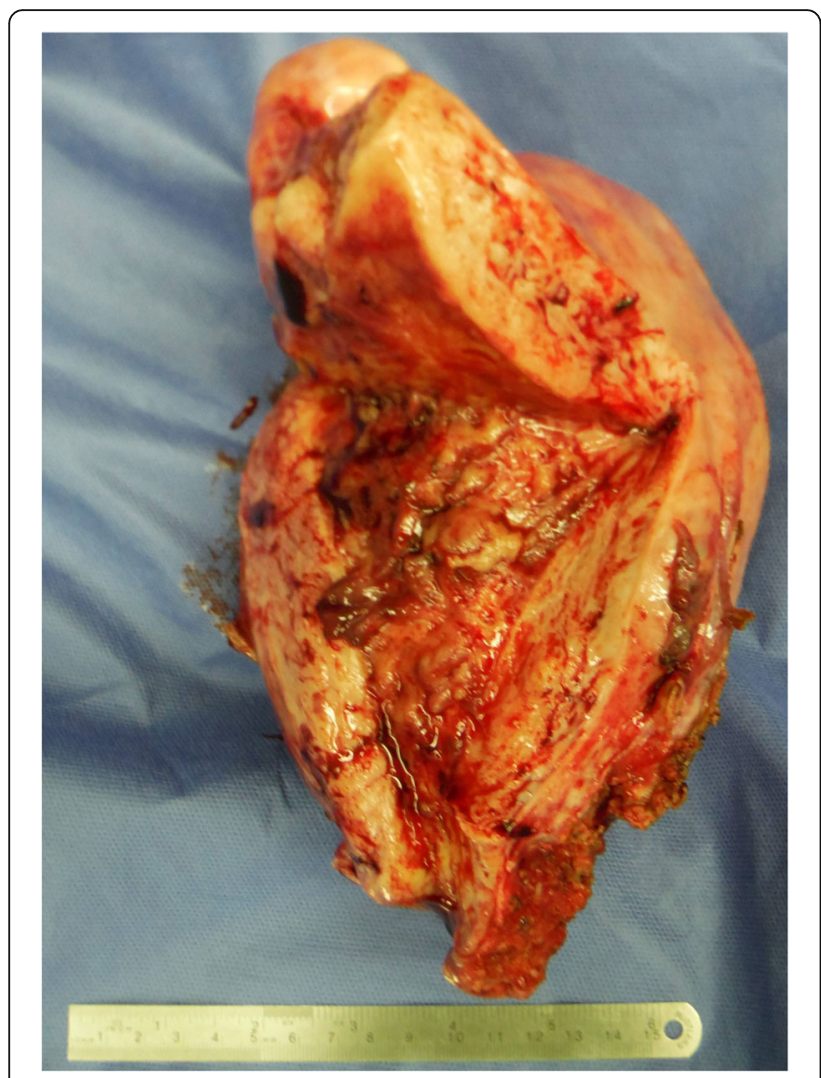

Fig. 3 The resected uterus

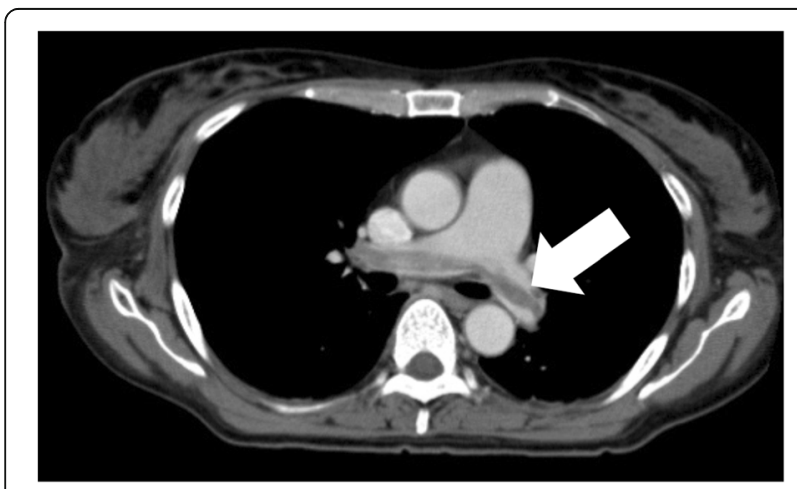

Fig. 4 Chest contrast-enhanced computed tomography shows a giant thrombus in the pulmonary artery (arrow) hysterectomy and ovariectomy were performed earlier, 11 days after the initial bleeding (Fig. 3). We discontinued heparin therapy after surgery. Histopathological assessment revealed no malignancy, and diagnoses of adenomyosis, uterine myoma, and ovarian endometriosis were established. On day 14 after the initial bleeding, whole-body contrast-enhanced CT revealed pulmonary thromboembolism, (Fig. 4) which was asymptomatic, and heparin was re-administered. On day 20 after the initial bleeding, because her pulmonary thromboembolism tended to dissolve, we switched the anticoagulant therapy from heparin to edoxaban $60 \mathrm{mg} /$ day for 6 months. The patient's D-dimer levels dropped immediately after surgery, and CA125 and CA19-9 levels returned to normal range $(12.0 \mathrm{U} / \mathrm{mL}$ and $5.6 \mathrm{U} / \mathrm{mL}$, respectively) 3 months after surgery (Fig. 5). Since her symptoms had improved and her NIHSS score was 0 , she was discharged with a modified Rankin Scale score of one, 42 days after she experienced CI. The patient had not experienced additional ischemic events 15 months postoperatively (Fig. 6a, b).

\section{Discussion and conclusions}

Herein, we report the case of a patient with adenomyosis accompanied by multiple uterine myomas and ovarian endometriosis that led to systemic thromboembolism, including multiple CIs with right middle cerebral artery occlusion. We suggested that her untreated adenomyosis accompanied by uterine myoma and ovarian endometriosis was associated with elevated D-dimer, CA125, and CA19-9 levels and caused thromboembolic CI, similar to Trousseau's syndrome.

A systematic literature search was conducted to identify cases of CI associated with adenomyosis through a PubMed search between November 2012 and September 2020 with the keywords "adenomyosis" and "cerebral infarction," and 15 cases including our case were identified (Table 1) [1-8]. Table 1 demonstrates that most patients had decreased $\mathrm{Hb}$ and elevated D-dimer and CA125 levels, which occurred during menstruation in half of the patients. Four of the 15 patients had major cerebral artery occlusion. Five of the 15 patients eventually underwent hysterectomy to prevent recurrent $\mathrm{CI}$, and there was no subsequent recurrence of $\mathrm{CI}$ in these patients. Patients having fever were reported in 3 cases $[2,5,7]$. Furthermore, systemic embolism involving the fingers, kidneys, and spleen, as well as thrombi in the brachiocephalic trunk and left subclavian artery were reported in 3 cases $[1,2]$. In this patient (Table 1 ; case 15), CA125 and D-dimer levels were significantly more elevated than in any other case. In addition, 


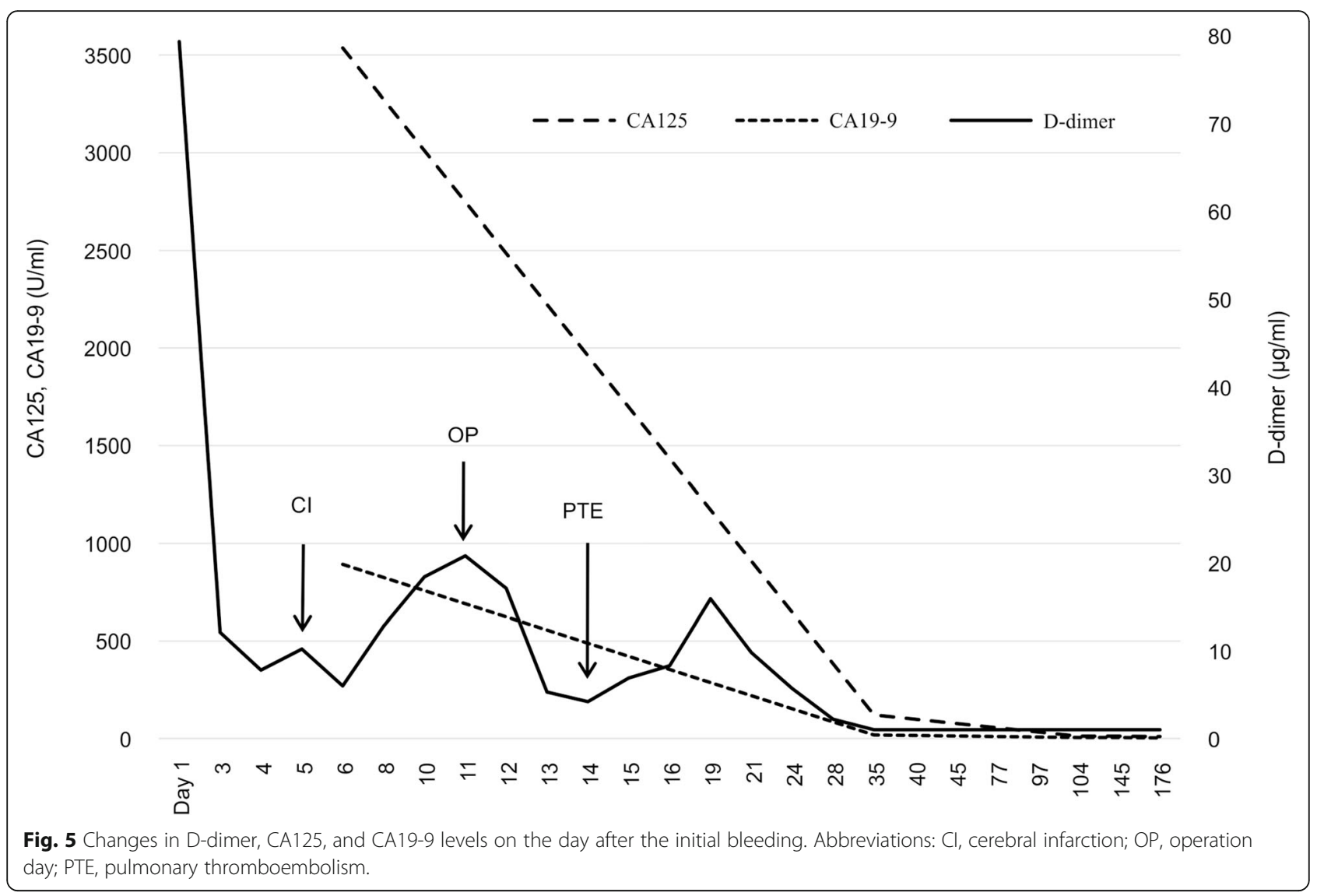

systemic embolism, including pulmonary thromboembolism, bilateral renal infarctions, and multiple CIs, occurred. Out of the 14 patients in the literature, there was no case in which adenomyosis was accompanied by a benign gynecological tumor such as uterine myoma or ovarian endometriosis or in which endovascular thrombectomy was required.

The levels of tumor markers, such as CA125, that fluctuate during the menstrual cycle reach a peak during menstruation [9]. Severe adenomyosis with a uterine size $>12$ weeks' gestation or volume beyond $240 \mathrm{~cm}^{3}$ has been shown to raise CA125 levels [10]. CA125 levels have been observed to be significantly elevated in patients with endometriosis accompanied by adenomyosis, and CA19-9 levels increased significantly following the progression of endometriosis [11]. Furthermore, patients with both uterine myoma and ovarian endometriosis, which were at a risk of developing cancer, have been shown to have elevated CA125 and CA19-9 levels [12]. Therefore, we considered that CA125 and CA19-9 levels may easily have increased because of menstruation and adenomyosis accompanied by uterine myoma and ovarian endometriosis.

Additionally, elevated CA125 levels may be associated with CI [13] and they correlate with D-dimer levels under a high tumor burden [14]. Carcinoma mucins, such as CA125 and CA19-9 promote thrombosis through increased leukocytes and platelets activities $[15,16]$. Thus, carcinoma mucins were thought to play an important role in hypercoagulation. Yin et al. [4] reported that patients with adenomyosis had a higher risk of developing CI during menstruation. Aso et al. [2] also suggested that middle-aged women with adenomyosis were at a high risk of CI when Ddimer, CA125, and CA19-9 levels were elevated. Moreover, they concluded that anticoagulant therapy, including direct oral anticoagulants, could not prevent CI. However, hysterectomy was the most effective prevention of CI.

Furthermore, Zhao et al. [5] reported that infection was a potential risk for developing acute CI with adenomyosis. Since our patient also had fever and her laboratory tests demonstrated elevated WBC and CRP, 


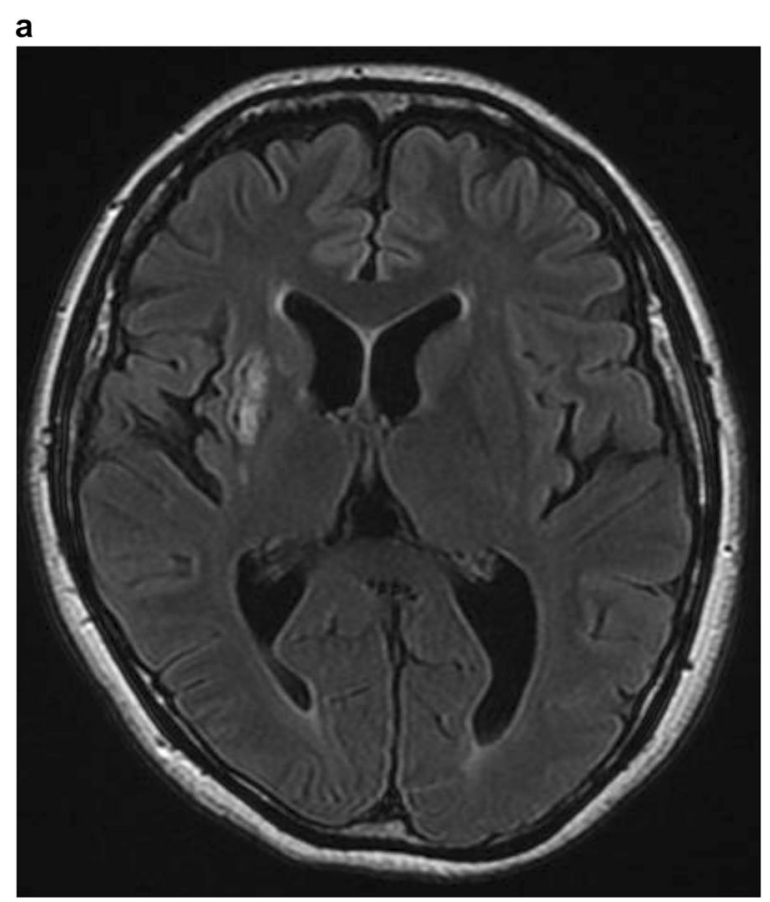

b

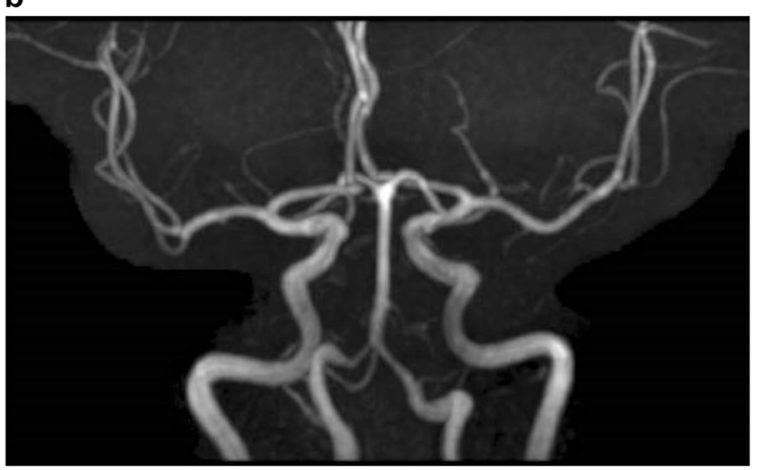

Fig. 6 Brain magnetic resonance image at 11 months postoperatively(a-b) No cerebral infarction can be observed, and the major cerebral arteries are well visualized

infection might have furthered her hypercoagulability in addition to both menstruation and elevated CA125, CA19-9, and D-dimer levels, resulting in CI with major cerebral artery occlusion.

In the present case, we suggest that the patient's tumor markers, such as CA125 and CA19-9, were significantly elevated due to menstruation and severe adenomyosis accompanied by multiple uterine myomas and ovarian endometriosis that were shown to be benign on histopathological examination [9-12]. We also suggest that these carcinoma mucins activated coagulation, caused thromboembolism, and resulted in the development of $\mathrm{CI}$ and systemic embolism [13-16]. In the case of CI due to thromboembolism, we would expect that endovascular thrombectomy would be effective. However, mechanisms for thromboembolism caused by a benign gynecological disease that elevated CA125, CA19-9, and D-dimer levels are not fully elucidated. Thus, further studies are required.

In conclusion, this case suggests that adenomyosis accompanied by a benign gynecological tumor and menstruation is associated with elevated D-dimer, CA125, and CA19-9 levels and increases the risk of systemic embolism including CI. Moreover, this clinical situation may cause major cerebral artery occlusion requiring endovascular thrombectomy, and hysterectomy may be the most effective therapy to prevent CI. 
Table 1 Clinical profiles of previous cases of cerebral infarction associated with adenomyosis

\begin{tabular}{|c|c|c|c|c|c|c|c|c|c|c|}
\hline Case & Age & $\begin{array}{l}\text { Occurrence during } \\
\text { menstruation }\end{array}$ & $\begin{array}{l}\text { CA125 } \\
(\mathrm{U} / \\
\mathrm{mL})\end{array}$ & $\begin{array}{l}\text { CA19- } \\
9 \\
(\mathrm{U} / \\
\mathrm{mL})\end{array}$ & $\begin{array}{l}\text { D- } \\
\text { dimer } \\
(\mu \mathrm{g} / \\
\mathrm{mL})\end{array}$ & $\begin{array}{l}\mathrm{Hb} \\
(\mathrm{g} / \\
\mathrm{dL})\end{array}$ & Major cerebral artery & Treatment for $\mathrm{Cl}$ & $\begin{array}{l}\text { Treatment for } \\
\text { denomyosis }\end{array}$ & $\begin{array}{l}\text { Recurrence } \\
\text { of } \mathrm{Cl}\end{array}$ \\
\hline 1 [1] & 45 & - & 159 & - & 1.1 & 8.4 & Normal & $\begin{array}{l}\text { Heparin, } \\
\text { antiplatelet } \\
\text { therapy }\end{array}$ & GnRH agonist & - \\
\hline $2[1]$ & 44 & - & - & - & - & 7 & Normal & Heparin, warfarin & GnRH agonist & - \\
\hline $3[1]$ & 50 & + & 42.6 & - & 0.57 & 6.9 & Normal & Aspirin & GnRH agonist & - \\
\hline \multirow[t]{2}{*}{$4[1]$} & 42 & + & 1750 & - & 6 & 8.6 & Normal & $\begin{array}{l}\text { Antiplatelet } \\
\text { therapy }\end{array}$ & GnRH agonist & + \\
\hline & & & & & & & & Heparin, warfarin & GnRH agonist & - \\
\hline $5[6]$ & 59 & - & 334.8 & - & 7 & - & - & $\begin{array}{l}\text { Antithrombotic } \\
\text { therapy }\end{array}$ & - & - \\
\hline $6[7]$ & 48 & - & 901 & 1791 & 1.9 & 8.5 & $\begin{array}{l}\text { Occlusion of the left M1 } \\
\text { of MCA }\end{array}$ & Heparin, warfarin & Hysterectomy & - \\
\hline $7[8]$ & 49 & - & 379 & 69.2 & 3.99 & 9.9 & Normal & Anticoagulant & Hysterectomy & - \\
\hline \multirow[t]{2}{*}{8 [2] } & 44 & + & 2115 & 1824 & 17 & 10.3 & $\begin{array}{l}\text { Severe stenosis in the } \\
\text { right M2of MCA }\end{array}$ & $\begin{array}{l}\text { Heparin, } \\
\text { rivaroxaban }\end{array}$ & GnRH agonist & + \\
\hline & & & & & & & & & Hysterectomy & - \\
\hline 9 [3] & 42 & - & 395 & - & 1.4 & - & $\begin{array}{l}\text { Occlusion of the left M2 } \\
\text { of MCA }\end{array}$ & Warfarin & - & - \\
\hline $\begin{array}{l}10 \\
{[3]}\end{array}$ & 50 & - & 143 & - & 3.7 & - & $\begin{array}{l}\text { After occlusion of the left } \\
\text { M1 of MCA, } \\
\text { partial reperfusion of } \\
\text { MCA }\end{array}$ & Rivaroxaban & - & - \\
\hline $\begin{array}{l}11 \\
{[4]}\end{array}$ & 34 & + & 937.1 & 462.5 & 1.05 & 13.4 & Normal & - & - & - \\
\hline $\begin{array}{l}12 \\
{[4]}\end{array}$ & 37 & + & 735.7 & 43.2 & 12.04 & 10.8 & Normal & - & - & - \\
\hline $\begin{array}{l}13 \\
{[4]}\end{array}$ & 46 & + & 546.5 & 1076.6 & 2.34 & 12.1 & Stenosis of the right PCA & - & Hysterectomy & - \\
\hline $\begin{array}{l}14 \\
{[5]}\end{array}$ & 34 & + & 937.7 & - & 27.4 & 11.2 & $\begin{array}{l}\text { Severe stenosis in the } \\
\text { right M1 of MCA }\end{array}$ & $\begin{array}{l}\text { Heparin, } \\
\text { antiplatelet } \\
\text { therapy }\end{array}$ & - & - \\
\hline 15 & 48 & + & 3536.2 & 892.1 & 79.3 & 8.2 & $\begin{array}{l}\text { Occlusion of the right } \\
\text { M1 of MCA }\end{array}$ & $\begin{array}{l}\text { Heparin, } \\
\text { edoxaban } \\
\text { Endovascular } \\
\text { thrombectomy }\end{array}$ & Hysterectomy & - \\
\hline
\end{tabular}

Abbreviations: $C A$ cancer antigen; $C l$ cerebral infarction; $G n R H$ gonadotropin-releasing hormone; $H b$ hemoglobin concentration; $M C A$ middle cerebral artery; $P C A$ posterior cerebral artery

\section{Abbreviations}

CA: Cancer antigen; Cl: Cerebral infarction; CRP: C-reactive protein level; $\mathrm{CT}$ : Computed tomography; Hb: Hemoglobin concentration; MRI: Magnetic resonance imaging; NIHSS: National Institutes of Health Stroke Scale; WBC: White blood cell count

\section{Acknowledgements}

Not applicable.

\section{Authors' contributions}

RA diagnosed, treated, and followed up the patient. RA drafted the manuscript and created the figures. SN contributed to the revision of the manuscript. HF, HY, and YK were involved in the surgery. All authors have read and approved the final manuscript.

\section{Funding}

Not applicable.

\section{Availability of data and materials}

Not applicable.

Ethics approval and consent to participate

Not applicable.

\section{Consent for publication}

Written informed consent was obtained from the patient for publication of this case report and any accompanying images.

\section{Competing interests}

The authors declare that they have no competing interests.

\section{Author details}

'Department of Neurosurgery, AOI Universal Hospital, 2-9-1, Tamachi, Kawasaki Ward, 210-0822 Kawasaki City, Kanagawa, Japan. ${ }^{2}$ Department of Neurosurgery, Showa University Fujigaoka Hospital, 1-30, Fujigaoka, Aoba 
Ward, 227-8501 Yokohama City, Kanagawa, Japan. ${ }^{3}$ Department of Neurosurgery, Showa University Northern Yokohama Hospital, 35-1, Chigasaki Chuo, Tsuzuki Ward, 224-8503 Yokohama City, Kanagawa, Japan.

Received: 30 September 2020 Accepted: 4 January 2021

Published online: 11 January 2021

\section{References}

1. Yamashiro K, Tanaka R, Nishioka K, Ueno Y, Shimura H, Okuma Y. et al. Cerebral infarcts associated with adenomyosis among middle-aged women. J Stroke Cerebrovasc Dis. 2012;21:910.e1-5.

2. Aso Y, Chikazawa R, Kimura Y, Kimura N, Matsubara E. Recurrent multiple cerebral infarctions related to the progression of adenomyosis: a case report. BMC Neurol. 2018;18:119.

3. Okazaki K, Oka F, Ishihara H, Suzuki M. Cerebral infarction associated with benign mucin-producing adenomyosis: report of two cases. BMC Neurol. 2018;18:166.

4. Yin X, Wu J, Song S, Zhang B, Chen Y. Cerebral infarcts associated with adenomyosis: a rare risk factor for stroke in middle-aged women: a case series. BMC Neurol. 2018;18:213.

5. Zhao $Y$, Zhang $Y$, Yang $Y$. Acute cerebral infarction with adenomyosis in a patient with fever: a case report. BMC Neurol. 2020;20:210.

6. Hijikata N, Sakamoto Y, Nito C, Matsumoto N, Abe A, Nogami A. et al. Multiple cerebral infarctions in a patient with adenomyosis on hormone replacement therapy: a case report. J Stroke Cerebrovasc Dis. 2016;25:e183 4.

7. Uchino K, Shimizu T, Mizukami H, Isahaya K, Ogura H, Shinohara K. et al Nonbacterial thrombotic endocarditis complicated by cerebral infarction in a patient with adenomyosis with high serum CA125 level; a case report. J Stroke Cerebrovasc Dis. 2018;27:e42-5.

8. Kim B, Kim SH, Kim T. Cerebral infarcts by nonbacterial thrombotic endocarditis associated with adenomyosis: a case report. J Stroke Cerebrovasc Dis. 2018:27:e50-3.

9. Kan YY, Yeh SH, Ng HT, Lou CM. Effect of menstruation on serum CA125 levels. Asia Oceania J Obstet Gynaecol. 1992;18:339 - 43.

10. Sheth SS, Ray SS. Severe adenomyosis and CA125. J Obstet Gynaecol. 2014; 34:79-81.

11. Harada T, Kubota T, Aso T. Usefulness of CA19-9 versus CA125 for the diagnosis of endometriosis. Fertil Steril. 2002;78:733-9.

12. Tsao KC, Hong JH, Wu TL, Chang PY, Sun CF, Wu JT. Elevation of CA 19 - 9 and chromogranin A, in addition to CA 125, are detectable in benign tumors in leiomyomas and endometriosis. J Clin Lab Anal. 2007;21:193-6.

13. Jovin TG, Boosupalli V, Zivkovic SA, Wechsler LR, Gebel JM. High titers of CA-125 may be associated with recurrent ischemic strokes in patients with cancer. Neurology. 2005;64:1944-5.

14. Tas F, Kilic L, Bilgin E, Keskin S, Sen F, Ciftci R. et al. Clinical and prognostic significance of coagulation assays in advanced epithelial ovarian cancer. Int J Gynecol Cancer. 2013:23:276 - 81.

15. Shao B, Wahrenbrock MG, Yao L, David T, Coughlin SR, Xia L. et al. Carcinoma mucins trigger reciprocal activation of platelets and neutrophils in a murine model of trousseau syndrome. Blood. 2011;118:4015-23.

16. Varki A. Trousseau's syndrome: multiple definitions and multiple mechanisms. Blood. 2007;110:1723-9.

\section{Publisher's Note}

Springer Nature remains neutral with regard to jurisdictional claims in published maps and institutional affiliations.

Ready to submit your research? Choose BMC and benefit from:

- fast, convenient online submission

- thorough peer review by experienced researchers in your field

- rapid publication on acceptance

- support for research data, including large and complex data types

- gold Open Access which fosters wider collaboration and increased citations

- maximum visibility for your research: over $100 \mathrm{M}$ website views per year

At $\mathrm{BMC}$, research is always in progress.

Learn more biomedcentral.com/submissions 